NBER WORKING PAPER SERIES

\title{
ESTIMATED EFFECTS OF RELATIVE PRICES \\ ON TRADE SHARES
}

Ray C. Fair

Working Paper No. 696

\author{
NATIOHAL BUREAU OF ECOUNOMIC RESEARCH \\ 1050 Massachusetts Avenue \\ Cambridge MA 02138 \\ June 1981
}

The research reported here is part of the NBER's research program in International Studies. Any opinions expressed are those of the author and not those of the National Bureau of Economic Research. 
ESTIMATED EFFECTS OF RELATIVE PRICES ON TRADE SHARES

ABSTRACT

Estimated effects of relative prices on trade shares are presented in this paper for 64 countries. The equations are estimated using pooled time series, cross section data under the assumption that the error term is serially correlated across time and heteroskedastic across countries. The results strongly indicate that relative prices have an important effect on trade shares.

The sensitivity of the properties of the multicountry model in Fair (1981a) to the endogenous treatment of trade shares is also examined. The addition of the trade share equations to the model has noticeable effects on the properties of the model regarding the effects of a depreciation. The sensitivity of trade shares to relative prices is an important channel in this version of the model through which a country's price of exports affects the demand for its exports.

Professor Ray C. Fair Cowles Foundation Department of Economics Box 2125, Yale Station Yale University New Haven, Connecticut 06520

(203) 436-0244 
ESTIMATED EFFECTS OF RELATIVE PRICES ON TRADE SHARES*

by

Ray C. Fair

\section{Introduction}

This paper grew out of my work on a multicountry econometric model (Fair (1981a, 1981b)). The trade matrix in this model is $64 \times 64$, and the trade shares have heretofore been taken to be exogenous. Estimated effects of relative prices on these trade shares are presented in this paper, and the sensitivity of the properties of the model to the endogenous treatment of trade shares is examined. The estimates are based on quarterly data from 1971 I through 1979IV (36 quarters) for 64 countries.

\section{The Data and the Trade-Share Equation}

The relevant variables are presented in Table 1. The raw data were taken from two tapes of the International Monetary Fund: the International Financial Statistics (IFS) tape and the Direction of Trade (DOT) tape. The way in which each variable was constructed is explained in brackets in Table 1. Some variables were taken directly from the tapes, and some were constructed from other variables. When "IFS" precedes a number in the table, this refers to the variable on the IFS tape with the particular number. The date of the tapes was October 1980.

\footnotetext{
* The research described in this paper was financed by Grant SOC77-03274 from the National Science Foundation.
} 
TABLE 1. The Variables for Country $i$ in Alphabetic order

$$
\begin{aligned}
& e_{i 75}=\text { average exchange rate in } 1975,1 c \text { per } \$ \text {. [ = IFSRF for 1975.] } \\
& \mathrm{e}_{i t}=\text { exchange rate, average for the quarter, } 1 c \text { per } \$ \text {. [=IFSRF.] } \\
& M \$_{i t}=\text { merchandise imports }(\mathrm{fob}) \text { in } \$ .\left[=I F S 71 \mathrm{~V} / \mathrm{e}_{i t} \cdot\right]
\end{aligned}
$$

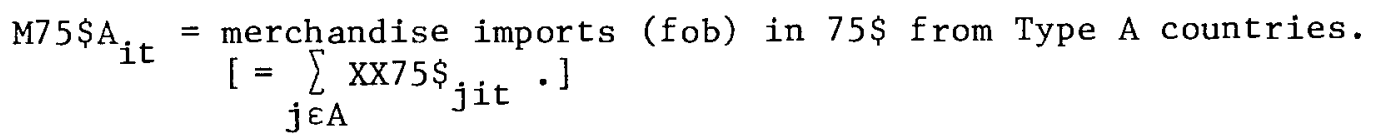

$$
\begin{aligned}
& \mathrm{PX}_{\text {it }}=\text { export price index, } 1975=1.0 . \quad[=\text { IFS74/100.] } \\
& \text { PX\$ }{ }_{i t}=\text { export price index, \$/75\$. }\left[=\left(\mathrm{e}_{i 75} \mathrm{PX}_{i t}\right) / \mathrm{e}_{i t} \cdot\right] \\
& \begin{aligned}
\mathrm{PY}_{\text {it }}= & \text { GNP or GDP deflator, } 1975=1.0 .[=(\text { IFS } 94 \mathrm{~A} \text { or IFS } 99 \mathrm{~B}) /(\text { IFS } 99 \mathrm{AP} \\
& \text { or IFS99BP or IFS99AR or IFS } 99 \mathrm{BR}) .]
\end{aligned} \\
& \mathrm{PY}_{i t}=\text { GNP or GDP deflator, \$/75\$. }\left[=\left(\mathrm{e}_{\mathrm{i} 75} \mathrm{PY}_{\mathrm{it}}\right) / \mathrm{e}_{\mathrm{it}-1} \cdot\right] \\
& X \$_{i t}=\text { merchandise exports }(f \mathrm{ob}) \text { in } \$ .\left[=\mathrm{IFS70}_{\mathrm{it}} \cdot\right]
\end{aligned}
$$

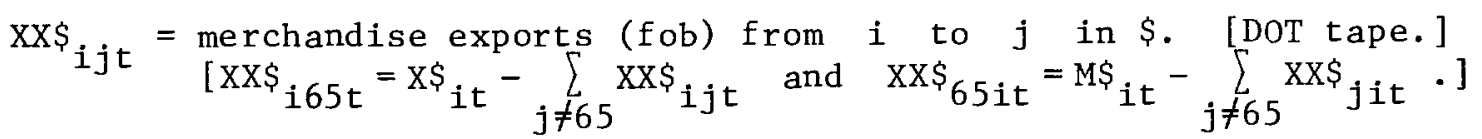

$$
\begin{aligned}
& {\left[x \$_{i j t}=0 \text { if } i=j \cdot\right]} \\
& x X 75 \$_{i j t}=\text { merchandise exports }(f o b) \text { from } i \text { to } j \text { in } 75 \$ . \quad[=x X \$ i j t / P X \$ i t \\
& \text { if } i \text { is a Type A country; = } 0 \text { otherwise.] }
\end{aligned}
$$

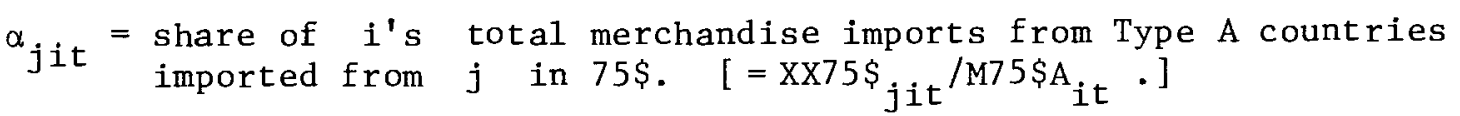

Notes: 1) $1 c=$ local currency.

2) $\$=$ U.S. dollar.

3) $\sum_{j \in A} \alpha_{j i t}=1$.

4) There is no country 48. In earlier versions this was Taiwan, but Taiwan has now been eliminated from the IMF tapes.

5) A Type A country is a country for which data on PX\$it exist. There are 47 Type A countries out of the total of 64 . 
The variable to be explained is $\alpha_{j i t}$, the share of country i's total merchandise imports from Type A countries imported from country j (in units of 75\$). Type A countries are countries for which data on exchange rates and export prices exist. These data, as can be seen in Table 1 , are needed to construct $\alpha_{j i t}$. There are 47 Type A countries out of the total of 64 . The $\alpha_{j i t}$ obey the property that $\sum_{j \in A} \alpha_{j i t}=1$, where the summation is over Type A countries.

The equation that was estimated for a given country $i$ is:

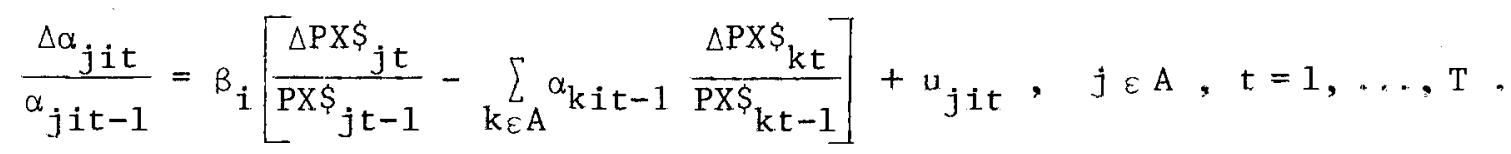

The total possible number of observations is (47 Type A countries) $\times(36$ quarters $)=1692$. There are 64 equations, one for each country $i$. Given that $\sum_{j \in A} \alpha_{j i t}=1$, equation (1) has the property that $\sum_{j \in A} \hat{\Delta \alpha}_{j i t}=0$, where $\hat{\Delta \alpha_{j i t}}$ is the predicted value of $\Delta \alpha_{j i t}$ from equation (1) using some estimate of $\beta_{i}$ and setting $u_{j i t}$ to zero for all $j$ and $t$. This is as desired to preserve the property that $\sum_{j \varepsilon A} \hat{\alpha}_{j i t}=1$. Equation (1) is restrictive in that the coefficient $B_{i}$ is the same across all values of $j$ (i.e., there is only one coefficient to estimate over all 1692 observations). If, say, $\alpha_{8 i t-1}=\alpha_{9 i t-1}$, then the percentage change in the share of country 8 corresponding to a given percentage change in country 8's export price is assumed to be the same as the percentage change in the share of country 9 corresponding to the same percentage change in country 9's export price.

Equation (1) is similar to the share equation estimated by Samuelson (1973). ${ }^{1}$ The differences are as follows. (1) Samuelson uses $\alpha_{j i t}$ in $\overline{1}$ other possible equations and approaches are discussed in Taplin (1973). 
place of $\alpha_{j i t-1}$ and $\mathrm{PX}_{j \mathrm{t}}$ in place of $\mathrm{PX}_{\mathrm{jt}-1}$ in the denominators. The use of the lagged values here is in keeping with the usual interpretation of percentage changes. (2) Samuelson adds two other variables to the equation: the relative change in capacity output and the relative change in demand pressure. These variables are designed to measure "relative non-price competitiveness" (p. 10). The problem with the capacity output variable is that while capacity output and exports tend to be positively correlated, the relationship between the two variables is not necessarily a structural one. Similarly, demand pressure and exports may be negatively correlated, but this is not necessarily a structural relationship. The assumption here is that any effects of capacity output and demand pressure on exports are reflected in the effects of these two variables on export prices. (3) Samuelson uses seasonal dummy variables, something which has not been done here.

Samuelson (p. 11) argues that equation (1) (without the capacity output and demand pressure variables) is a first-order approximation to the CES demand system of Armington (1969). This is not, however, correct. In the present case of one good per country, Armington's CES system is as follows. Consider the demand of a country for its own and other countries' goods. It's utility function is assumed to be:

$$
\mathrm{U}=\mathrm{U}(\mathrm{Z})
$$

where

$$
z=\left[b_{1} x_{1}^{-\rho}+b_{2} x_{2}^{-\rho}+\ldots+b_{K} x_{K}^{-\rho}\right]^{-1 / \rho}
$$

$\mathrm{K}$ is the number of countries and $x_{k}$ is the amount consumed of country $k$ 's good. Armington shows that maximizing (2) with respect to 
$\mathrm{X}_{1}, \ldots, \mathrm{X}_{\mathrm{K}}$ subject to (3) and the budget constraint $\mathrm{D}=\sum_{\mathrm{k}=1}^{\mathrm{K}} \mathrm{P}_{\mathrm{k}} \mathrm{X}_{\mathrm{k}}$, where $\mathrm{D}$ is nominal income of the country and $\mathrm{P}_{k}$ is the price of good k, leads to

$$
x_{j}=b_{j}^{\sigma} Z\left(\frac{P}{P}\right)^{-\sigma}, j=1, \ldots, k
$$

where $\sigma=1 /(1+\rho)$ and $P$ is a function only of $\mathrm{P}_{k}(\mathrm{k}=1, \ldots, \mathrm{k})$, $\mathrm{b}_{\mathrm{k}} \quad(\mathrm{k}=1, \ldots, \mathrm{k})$, and $\sigma$.

Now, multiplying equation (1) by $\alpha_{j i t-1}$, ignoring the error

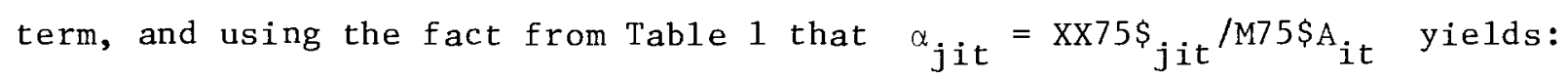

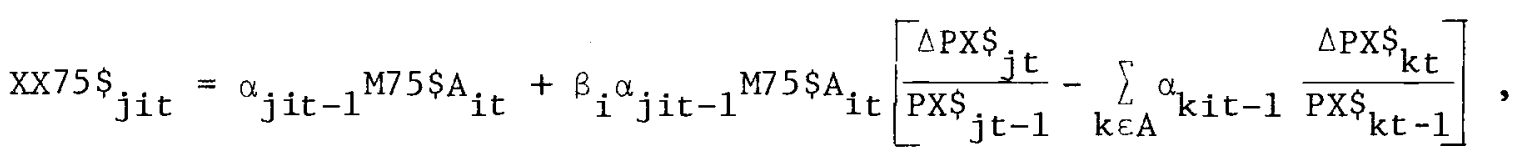

$$
\begin{aligned}
& \mathrm{j} \varepsilon \mathrm{A}, \mathrm{t}=1, \ldots, \mathrm{T} .
\end{aligned}
$$

Equation (1)' is the same as the equation derived by Samuelson (p. 11) except for the use of the lagged values rather than the current values of $\alpha$ and PX\$ . Samuelson argues that this equation is a first order approxi-mation to equation (4). This is not the case because $Z$, un1ike M75\$A $A_{i t}$, is not merely the weighted sum of imports: it is also a function of $\rho$ (and thus of $\sigma$ ). Likewise, $P$ is a function of $\rho$. Although in a loose sense equation (1)' is an approximation to (4), it seems better merely to argue direct1y that equation (1) may not be too bad an approximation to the true structure, rather than to appeal to the CES demand system. 
III. The Econometric Techniques

Equation (1) is an example in which there is a fairly large number of observations both across individuals (countries) and across time. It will be useful for purposes of this section to drop the $i$ subscript and rewrite (1) as

$$
y_{j t}=\beta x_{j t}+u_{j t}, j=1, \ldots, N, t=1, \ldots, T .
$$

$\mathrm{N}$ is the number of Type A countries. The error term is assumed to be autocorrelated across time and heteroskedastic across countries. In particular, it is assumed that

$$
u_{j t}=\rho_{j} u_{j t-1}+\varepsilon_{j t},
$$

(6) and (7) imply that

$$
\operatorname{Eu}_{j t}^{2}=\sigma_{j}^{2}
$$

$$
\mathrm{Eu}_{j t} \mathrm{u}_{k t}=0 \quad(j \neq k)
$$
is analyzed by Kmenta (1971, pp. 508-512). The model can be written

$$
E \varepsilon_{j t}^{2}=\sigma_{\varepsilon j}^{2}=\sigma_{j}^{2}\left(1-\rho_{j}^{2}\right)
$$

The model (5)-(8) (with an arbitrary number of explanatory variables) where $y=\left(y_{11}, \ldots, y_{1 T}, \ldots, y_{N 1}, \ldots, y_{N T}\right)^{\prime}, x=\left(x_{11}, \ldots, x_{1 T}, \ldots\right.$, $\left.\mathrm{x}_{\mathrm{N} 1}, \ldots, \mathrm{x}_{\mathrm{NT}}\right)^{\prime}$, and $\mathrm{u}=\left(\mathrm{u}_{11}, \ldots, \mathrm{u}_{1 \mathrm{~T}}, \ldots, \mathrm{u}_{\mathrm{N} 1}, \ldots, \mathrm{u}_{\mathrm{NT}}\right)^{\prime}$. The covariance matrix of $u$, denoted $\Omega$, is 
(11)

Euu $^{\prime}=\Omega=\left[\begin{array}{cccc}\sigma_{1}^{2} \mathrm{P}_{1} & 0 & \cdots & 0 \\ 0 & \sigma_{2}^{2} \mathrm{P}_{2} & \cdots & 0 \\ \vdots & \vdots & & \vdots \\ 0 & 0 & \cdots & \sigma_{\mathrm{N}}^{2} \mathrm{P}_{\mathrm{N}}\end{array}\right]$,

where

$$
P_{j}=\left[\begin{array}{ccccc}
1 & \rho_{j} & \rho_{j}^{2} & \ldots & \rho_{j}^{T-1} \\
\rho_{j} & 1 & \rho_{j} & \ldots & \rho_{j}^{T-2} \\
\vdots & \vdots & \vdots & & \vdots \\
\rho_{j}^{T-1} & \rho_{j}^{T-2} & \rho_{j}^{T-3} & \ldots & 1
\end{array}\right], j=1, \ldots, N .
$$

The generalized least squares (GLS) estimator of $\beta$ is

$$
\tilde{\beta}=\left(X^{\prime} \Omega^{-1} X\right)^{-1} X^{\prime} \Omega^{-1} y,
$$

with asymptotic covariance matrix $\left(\mathrm{X}^{\prime} \Omega^{-1} \mathrm{X}\right)^{-1}$. Under the assumption of normality, $\tilde{\beta}$ is also the maximum likelihood estimator.

The GLS estimator is not feasible because $\Omega$ is not known. It is possible, however, to estimate both $\beta$ and $\Omega$. Kmenta (pp. 510-511) proposes a three step procedure for doing this. An alternative procedure was used for the results in this study, a procedure that iterates between estimates of $\beta$ and estimates of $\Omega$ until convergence. The procedure is :

[1] Regress $y_{j t}$ on $x_{j t}$ using the $N \cdot T$ pooled observations. Let $\hat{\beta}$ denote the estimate of $\beta$ from this regression. 
[2] Compute:

$$
\begin{aligned}
& \hat{u}_{j t}=y_{j t}-\hat{B} x_{j t}, j=1, \ldots, N ; t=1, \ldots, T, \\
& \hat{\rho}_{j}=\frac{\sum_{t=2}^{T} \hat{u}_{j t} \hat{u}_{j t-1}}{\sum_{t=2}^{T} \hat{u}_{j t-1}^{2}}, j=1, \ldots, N, \\
& \hat{\varepsilon}_{j t}=\hat{u}_{j t}-\hat{\rho}_{j} \hat{u}_{j t-1}, j=1, \ldots, N ; t=2, \ldots, T, \\
& \hat{\sigma}_{\varepsilon j}^{2}=\sum_{t=2}^{T} \hat{\varepsilon}_{j t}^{2}, j=1, \ldots, N \text {, } \\
& y_{j t}^{*}=\frac{y_{j t}-\hat{\rho}_{j} y_{j t-1}}{\hat{\sigma}_{\varepsilon j}}, \quad x_{j t}^{*}=\frac{x_{j t}-\hat{\rho}_{j} x_{j t-1}}{\hat{\sigma}_{\varepsilon j}}, \\
& j=1, \ldots, N ; t=2, \ldots, T \text {. }
\end{aligned}
$$

[3] Regress $y_{j t}^{*}$ on $x_{j t}^{*}$ using the $N \cdot(T-1)$ pooled observations. This gives a new estimate of $\beta$.

[4] Repeat [2] and [3] using the new estimate of $\beta$. Keep repeating until successive estimates of $\beta$ are within a prescribed tolerance leve1.

An estimate of the covariance matrix of $\hat{\beta}$ is merely the covariance matrix computed on the last step from the pooled observations. Note that in going from [1] to [3] one observation is lost for each cross-sectional unit.

This procedure is a special case of the procedure discussed in Oberhofer and Kmenta (1974). They show under fairly general conditions 
(conditions that are satisfied in the present application) that if the procedure converges it converges to a solution of the first order maximizing conditions of the maximum likelihood estimator. As will be seen, the procedure converged quite rapidly for the results in this study.

This procedure does not lead to consistent estimates if $x_{j t}$ and $\varepsilon_{j t}$ are correlated. As will be discussed in Section $I V, x_{j t}$ and $\varepsilon_{j t}$ may be correlated in the present case. If one can find variables that are correlated with $x_{j t}$ but not with $\varepsilon_{j t}$, then an instrumental variables (IV) version of the above procedure can be used. Let $\mathrm{y}^{*}=\left(\mathrm{y}_{12}^{*}, \ldots, \mathrm{y}_{1 \mathrm{~T}}^{*}, \ldots, \mathrm{y}_{\mathrm{N} 2}^{*}, \ldots, \mathrm{y}_{\mathrm{NT}}^{*}\right)^{\prime}, \mathrm{x}^{*}=\left(\mathrm{x}_{12}^{*}, \ldots, \mathrm{x}_{1 \mathrm{~T}}^{*}, \ldots, \mathrm{x}_{\mathrm{N} 2}^{*}, \ldots, \mathrm{x}_{\mathrm{NT}}^{*}\right)^{\prime}$, and

$$
\mathrm{z}^{*}=\left[\begin{array}{ccc}
\mathrm{z}_{12,1}^{*} & \cdots & \mathrm{z}_{12, \mathrm{M}}^{*} \\
\vdots & & \vdots \\
\mathrm{z}_{1 \mathrm{~T}, 1}^{*} & \cdots & \mathrm{z}_{1 \mathrm{~T}, \mathrm{M}}^{*} \\
\vdots & & \vdots \\
\mathrm{z}_{\mathrm{N} 2,1}^{*} & & \mathrm{z}_{\mathrm{N} 2, \mathrm{M}}^{*} \\
\vdots & & \vdots \\
\mathrm{z}_{\mathrm{NT}, 1}^{*} & & \mathrm{z}_{\mathrm{NT}, \mathrm{M}}^{*}
\end{array}\right] \text {, }
$$

where $z_{j t, m}^{*}=z_{j t, m} / \hat{\sigma}_{\varepsilon j} \cdot z_{j t, m}$ is the $j t$ value of variable $m$. The total number of $Z$ variables is $M$. They are assumed to be correlated with $x_{j t}$ but not with $\varepsilon_{j t}$. In the regular version of the procedure the estimate of $\beta$ in step [3] is $\left(X^{*} X^{*}\right)^{-1} X^{*} y^{*}$. An estimate of the asymptotic covariance matrix of the estimator is $\left(X^{*} X^{*}\right)^{-1}$. In the IV version the estimate of $\beta$ in step [3] is $\left(\hat{X}^{*} X^{*}\right)^{-1} \hat{X}^{*} y^{*}$, where $\hat{X}^{*}=Z^{*}\left(Z^{*} Z^{*}\right)^{-1} Z^{*} X^{*}$. An estimate of the asymptotic covariance matrix of this estimator is $\left(\hat{X}^{*} X^{*}\right)^{-1}$. Since $y_{j t-1}$ and $x_{j t-1}$ are 
part of $y_{j t}^{*}$ and $x_{j t}^{*}$, respectively, they should be included among the $Z$ variables if they are not correlated with $\varepsilon_{j t}$. In other words, they should serve as their own instruments. If they are not included, they will be treated as endogenous along with $x_{j t}$. Note that $z_{j t, m}^{*}$, unlike $y_{j t}^{*}$ and $x_{j t}^{*}$, is not a function of $\hat{\rho}_{j}$.

IV. The Estimates

The results of estimating equation (1) for each of the 64 countries are presented in Table 2. There are 47 Type A countries, and the basic estimation period is 1971I-1979IV (36 quarters). If every country traded with all 47 Type A countries every quarter, the number of observations for each estimated equation would be $35 \times 47=1645$. In practice, not every country trades with every other. It is also true that for some quarters (typically the early and late quarters) data on PXS $j t$ do not exist for an otherwise Type A country. These two facts mean the number of observations for a given equation is less than 1645. The exact number for each equation is presented in Table 2 .

The first set of results in Table 2 is quite remarkable. ${ }^{2}$ For only three countries--Yugoslavia, Mexico, and China--is the sign of the coefficient estimate positive (and thus contrary to what is expected). of the remaining 61 countries, 48 have t-statistics greater than or equal to 2.0 in absolute value and only 5 have t-statistics less than 1.0 in

2 The average number of iterations for the procedure (across the 64 equations) was 4.5 for a tolerance level of 0.01 percent. The largest number of iterations for a given equation was 14 . The time taken to estimate the 64 equations on the IBM $370-158$ at Yale was about 5.5 minutes using a program written by the author. In a few cases the initial estimate of a serial correlation coefficient was greater than one in absolute value, and in these cases the estimate was constrained to be zero. This was also done for the IV results. 
TABLE 2. Estimates of Equation (1) for 64 Countries

\begin{tabular}{|c|c|c|c|c|c|c|c|c|c|}
\hline & \multirow[b]{2}{*}{ Country } & \multicolumn{3}{|c|}{$\begin{array}{l}\text { Regular Procedure } \\
\text { Bastc Sample Perlods }\end{array}$} & \multicolumn{3}{|c|}{$\begin{array}{l}\text { Regular Procedure } \\
\text { Smaller Sample Perlods }\end{array}$} & \multicolumn{2}{|c|}{$\begin{array}{c}\text { IV Procedure } \\
\text { Smaller Sample } \\
\text { Perlods }\end{array}$} \\
\hline & & $\hat{B}_{1}$ & $\begin{array}{c}t- \\
\text { statistic }\end{array}$ & $\begin{array}{l}\text { No. of } \\
\text { Obs. }\end{array}$ & $\hat{\beta}_{1}$ & $\begin{array}{c}t- \\
\text { statistic }\end{array}$ & $\begin{array}{c}\text { No. of } \\
\text { Obs. }\end{array}$ & $\hat{B}_{1}$ & statistic \\
\hline 1 & U.S. & -0.312 & $(-5.01)$ & 1551 & -0.249 & $(-3.91)$ & 1302 & -0.033 & $(-0.20)$ \\
\hline 2 & Canada & -0.333 & $(-3.14)$ & 1460 & -0.260 & $(-3.03)$ & 1222 & 0.114 & $(0.51)$ \\
\hline 3 & Japan & -0.303 & $(-7.80)$ & 1556 & -0.344 & $(-8.15)$ & 1301 & -0.156 & $(-1.63)$ \\
\hline 4 & Austria & -0.290 & $(-3.15)$ & 1374 & -0.300 & $(-3.27)$ & 1155 & -0.616 & $(-2.55)$ \\
\hline 5 & Belgium & -0.434 & $(-5.85)$ & 1495 & -0.443 & $(-6.63)$ & 1279 & -0.475 & $(-2.77)$ \\
\hline 6 & Denmark & -0.457 & $(-4.04)$ & 1414 & -0.383 & $(-3.17)$ & 1202 & -0.394 & $(-1.19)$ \\
\hline 7 & France & -0.258 & $(-6.47)$ & 1538 & -0.270 & $(-6.11)$ & 1310 & -0.401 & $(-3.64)$ \\
\hline 8 & Germany & -0.231 & $(-5.34)$ & 1543 & -0.275 & $(-6.02)$ & 1308 & -0.228 & $(-2.10)$ \\
\hline 9 & Italy & -0.300 & $(-8.48)$ & 1540 & -0.293 & $(-8.01)$ & 1310 & -0.548 & $(-5.77)$ \\
\hline 10 & Netherlands & -0.553 & $(-10.18)$ & 1518 & -0.525 & $(-9.24)$ & 1288 & -0.498 & $(-2.65)$ \\
\hline 11 & Norway & -0.445 & $(-2.75)$ & 1404 & -0.374 & $(-2.98)$ & 1194 & -0.400 & $(-1,38)$ \\
\hline 12 & Sweden & -0.387 & $(-4.13)$ & 1467 & -0.379 & $(-4.12)$ & 1243 & 0.137 & $(0.54)$ \\
\hline 13 & Switzerland & -0.416 & $(-3.73)$ & 1439 & -0.367 & $(-3.03)$ & 1191 & -0.501 & $(-1 \cdot 26)$ \\
\hline 14 & U.K. & -0.309 & $(-6.35)$ & 1554 & -0.299 & $(-5.40)$ & 1300 & -0.246 & $(-2.03)$ \\
\hline 15 & Finland & -0.371 & $(-3.27)$ & 1361 & -0.397 & $(-3.70)$ & 1168 & -0.551 & $(-2.38)$ \\
\hline 16 & Greece & -0.555 & $(-5.78)$ & 1403 & -0.556 & $(-6.85)$ & 1184 & -0.984 & $(-4.72)$ \\
\hline 17 & Ireland & -0.715 & $(-7.30)$ & 1322 & -0.729 & $(-6.56)$ & 1053 & -0.747 & $(-4 \cdot 33)$ \\
\hline 18 & Portugal & -0.470 & $(-3.24)$ & 1321 & -0.434 & $(-3.99)$ & 1131 & -0.272 & $(-1.30)$ \\
\hline 19 & Romania & -0.340 & $(-3.16)$ & 1236 & -0.199 & $(-1.58)$ & 956 & -0.247 & $(-1.02)$ \\
\hline 20 & Spain & -0.146 & $(-2.75)$ & 1478 & -0.158 & $(-2.95)$ & 1254 & -0.094 & $(-0.85)$ \\
\hline 21 & Turkey & -0.421 & $(-2.90)$ & 1299 & -0.373 & $(-2.55)$ & 1076 & -0.627 & $(-2.68)$ \\
\hline 22 & Yugoslavia & 0.328 & $(2.11)$ & 1313 & 0.306 & $(1.89)$ & 1086 & -0.289 & $(-0.79)$ \\
\hline 23 & Australia & -0.388 & $(-5.54)$ & 1498 & -0.428 & $(-6.64)$ & 1269 & -0.347 & $(-2.39)$ \\
\hline 24 & New Zealand & -0.385 & $(-3.05)$ & 1275 & -0.421 & $(-4.15)$ & 1120 & -0554 & $(-2.33)$ \\
\hline 25 & South Africa & -0.302 & $(-1.89)$ & 1109 & -0.238 & $(-1,43)$ & 877 & -0.500 & $(-1.17)$ \\
\hline 26 & Algerla & -0.631 & $(-2.00)$ & 1045 & 0.537 & $(1.26)$ & 817 & 1.121 & $(0.84)$ \\
\hline 27 & Indonesia & -0.395 & $(-1.99)$ & 1137 & -0.231 & $(-1.29)$ & 949 & 0.118 & $(0.29)$ \\
\hline 28 & Iran & -0.397 & $(-3.52)$ & 1324 & -0.669 & $(-2.30)$ & 1017 & -0.242 & $(-0.32)$ \\
\hline 29 & Iraq & -0.185 & $(-0.73)$ & 1257 & -0.362 & $(-1.33)$ & 1002 & -1.568 & $(-3.02)$ \\
\hline 30 & Kuwait & -0.681 & $(-5.87)$ & 1265 & -0.835 & $(-4.32)$ & 1015 & -1.379 & $(-3.53)$ \\
\hline 31 & Libya & -0.675 & $(-7.91)$ & 1085 & -0.558 & $(-1.89)$ & 869 & 1.396 & $(1.45)$ \\
\hline 32 & N1geria & -0.611 & $(-6.57)$ & 1209 & -0.613 & $(-2.15)$ & 987 & 1.176 & (1.11) \\
\hline $\begin{array}{l}33 \\
34\end{array}$ & Saudi Arabia & -0.683 & $(-7.68)$ & 1346 & -0.666 & $(-4.32)$ & 1029 & -1.154 & $(-3.39)$ \\
\hline 34 & $\begin{array}{c}\text { United Arab } \\
\text { Emirates }\end{array}$ & -0.689 & $(-5.01)$ & 979 & -0.774 & $(-4.07)$ & 746 & -0.916 & $(-2.80)$ \\
\hline 35 & Venezuela & -0.448 & $(-2.81)$ & 1210 & -0.355 & $(-1.81)$ & 1019 & 1.339 & $(1.65)$ \\
\hline 36 & Argentina & -0.855 & $(-5.09)$ & 1211 & -1.003 & $(-4.46)$ & 970 & -1.161 & $(-1.27)$ \\
\hline 37 & Brazil & -0.358 & $(-5.36)$ & 1379 & -0.336 & $(-4.65)$ & 1172 & -0.408 & $(-2.80)$ \\
\hline 38 & Chile & -0.303 & $(-1.58)$ & 1194 & -0.271 & $(-1.33)$ & 1033 & -0.842 & $(-1.62)$ \\
\hline 39 & Colombia & -0.417 & $(-1.99)$ & 1052 & -0.252 & $(-1.09)$ & 845 & -0.938 & $(-0.93)$ \\
\hline 40 & Mexico & 0.001 & $(0.00)$ & 1221 & 0.179 & $(0.83)$ & 1038 & 0.974 & $(1.63)$ \\
\hline 41 & Peru & -0.537 & $(-2.50)$ & 1069 & -0.374 & $(-1.45)$ & 913 & -1.449 & $(-1.17)$ \\
\hline 42 & Egypt & -0.176 & $(-1.84)$ & 1269 & -0.026 & $(-0.25)$ & 954 & -0.201 & $(-1.19)$ \\
\hline 43 & Israel & -0.626 & $(-3.42)$ & 1195 & -0.704 & $(-3.20)$ & 1023 & -0.507 & $(-0.76)$ \\
\hline 44 & Jordan & -0.645 & $(-4,70)$ & 1148 & -0.847 & $(-4.47)$ & 895 & -1.138 & $(-3.66)$ \\
\hline 45 & Lebanon & -0.724 & $(-12.54)$ & 1294. & -0.259 & $(-0.90)$ & 983 & -0.376 & $(-0.50)$ \\
\hline 46 & Syria & -1.235 & $(-4.74)$ & 1164 & -1.453 & $(-4.76)$ & 869 & -1.955 & $(-2.44)$ \\
\hline 47 & Bangladesh & -0.314 & $(-0.39)$ & 819 & -1.239 & $(-1.41)$ & 635 & -1.592 & $(-0.80)$ \\
\hline 49 & Hong Kong & -0.413 & $(-3.91)$ & 1345 & -0.462 & $(-4.15)$ & 1184 & -0.638 & $(-2.30)$ \\
\hline 50 & Ind Ia & -0.408 & $(-3.97)$ & 1287 & -0.563 & $(-4.25)$ & 1009 & -0.581 & $(-2.63)$ \\
\hline 51 & Korea & -0.339 & $(-3.75)$ & 1184 & -0.390 & $(-3.75)$ & 1044 & -0.669 & $(-2.98)$ \\
\hline 52 & Malaysia & -0.569 & $(-5.44)$ & 1172 & -0.640 & $(-5.63)$ & 1017 & -1.050 & $(-2.79)$ \\
\hline 53 & Pakistan & -0.550 & $(-5.33)$ & 1193 & -0.503 & $(-4.55)$ & 986 & -0.809 & $(-3.87)$ \\
\hline 54 & Philippines & -0.477 & $(-5.52)$ & 1245 & -0.450 & $(-5.95)$ & 1063 & -0.422 & $(-2.72)$ \\
\hline 55 & Singapore & -0.462 & $(-6.60)$ & 1301 & -0.341 & $(-4.69)$ & 1122 & -0.158 & $(-1.03)$ \\
\hline 56 & Thailand & -0.496 & $(-4.49)$ & 1235 & -0.422 & $(-4.43)$ & 1054 & -1.346 & $(-3.97)$ \\
\hline 57 & Bulgaria & -0.044 & $(-0.15)$ & 1092 & 0.056 & $(0.18)$ & 873 & 0.069 & $(0.09)$ \\
\hline 58 & China & 0.315 & $(0.88)$ & 1089 & 0.800 & $(1.86)$ & 891 & 1.037 & $(0.89)$ \\
\hline 59 & Cuba & -0.522 & $(-0.80)$ & 800 & -0.620 & $(-0.87)$ & 655 & 5.485 & $(2.25)$ \\
\hline 60 & Czechoslovakia & -0.325 & $(-1.41)$ & 1270 & -0.195 & $(-0.71)$ & 1025 & 0.858 & $(1.18)$ \\
\hline 61 & E. Germany & -0.675 & $(-5.28)$ & 1112 & -0.774 & $(-2.60)$ & 894 & 0.240 & $(0.31)$ \\
\hline 62 & Hungary & -0.374 & $(-2.51)$ & 1178 & -0.098 & $(-0.46)$ & 969 & -0.442 & $(-0.89)$ \\
\hline 63 & Poland & -0.136 & $(-0.60)$ & 1270 & -0.032 & $(-0.13)$ & 1016 & 0.615 & $(0.87)$ \\
\hline 64 & U.S.S.R. & -0.188 & $(-1.53)$ & 1196 & 0.393 & $(1.58)$ & 992 & 2.210 & $(3.03)$ \\
\hline 65 & ROW & -0.165 & $(-1.26)$ & 1709 & -0.145 & $(-0.99)$ & 1446 & -0.201 & $(-0.41)$ \\
\hline
\end{tabular}


absolute value. These results thus seem to provide rather strong support for the hypothesis that relative prices have an important effect on trade shares.

These results are so good that they lead one to be suspicious that something else is going on. One possible problem is that PX\$ $\mathrm{jt}$ is used both in the construction of the data for $\alpha_{j i t}$ (see Table 1) and in the explanation of $\alpha_{j i t}$. If PXS $_{j t}$ is measured with error, this is 1ikely to lead to a negative correlation between $\frac{\Delta \mathrm{PX} j \mathrm{jt}}{\mathrm{PX}{ }_{j t-1}}-\sum_{k \in A} \alpha_{k i t-1} \frac{\Delta \mathrm{PXS} k \mathrm{PX}}{\mathrm{PXt}-1}$ and the error term in equation (1) and thus to an estimate of $\beta_{i}$ that is biased downward. To test for this, equation (1) was estimated by the IV procedure. Five variables were used as $Z$ variables: a constant term,

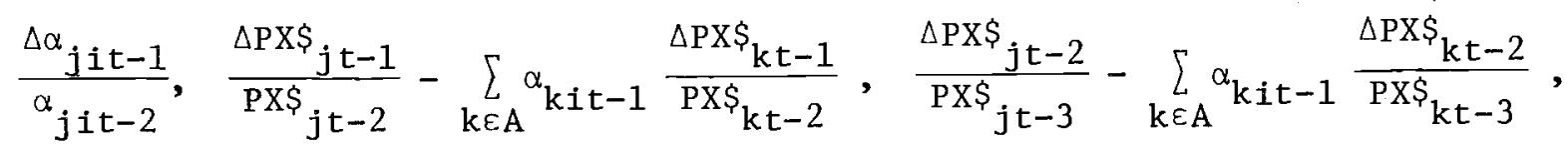
and $\frac{\Delta P Y \$_{j t}}{P Y \$_{j t-1}}-\sum_{k \in A} \alpha_{k i t-1} \frac{\Delta P Y \$_{k t}}{P Y \$_{k t-1}}$. The key variable in this choice is PY ${ }_{j t}$. This variable is defined in Table 1 . It is the GNP deflator converted to dollars using the exchange rate of the previous period: $\mathrm{PYS}_{j \mathrm{t}}=\left(\mathrm{e}_{j 75} \mathrm{PY}_{j t}\right) / \mathrm{e}_{j t-1}$. This variable is 1ikely to be correlated with PXS $_{j t}$, and it has not been used in the construction of the data for $\alpha_{j i t}$. The use of PY jt $_{\text {t }}$ required that a few more observations be dropped due to lack of data. The second set of results in Table 2 is the same as the first set except for the use of the shorter sample periods. The second set of results is similar to the first, although there are now six countries with a positive coefficient estimate instead of three. The third set of results is for the IV procedure. ${ }^{3}$ These results do not indicate that

3 The average number of iterations in this case was 5.7 . The largest number of iterations for a given equation was 16 . The time taken to estimate the 64 equations in this case was about 12 minutes. 
the non IV estimates are biased downward. Consider the first 15 countries, which are the main countries in the model. For 7 of the 15 the IV estimates are greater than the non IV estimates, but for the other 8 they are smaller. The estimates for the other countries are also not systematically different. (The IV estimates are not as precise, as expected, and they tend to be more erratic for the smaller countries.) It thus does not appear that the non IV estimates are biased downward, and so it seems that relative prices do have an important effect on trade shares. For each estimated equation there are $N$ estimates of $\rho_{j}$ and $N$ estimates of $\sigma_{\varepsilon j}$, where $N$ is the number of Type A countries that the given country trades with. A subset of these estimates is presented in Table 3. Estimates of $\rho_{j}$ and $\sigma_{\varepsilon j}$ for the first 15 countries for each of the first 15 equations are presented. Almost all of the estimates of $\rho_{j}$ are negative, which is as expected given that the left hand side variable is in change form. The estimates of $\sigma_{\varepsilon j}$ range from a low of 4 percent to a high of 94 percent. (Remember that the standard errors are for the percentage changes in the shares, not the absolute changes.) Most of the estimates are less than 20 percent.

\section{The Trade Share Equations in a Multicountry Model}

The sensitivity of the properties of the model in Fair (1981a) to the endogenous treatment of trade shares is examined in this section. Two main questions are considered. The first is how the fit of the mode1 is affected by the inclusion of the trade share equations, and the second is how the multiplier properties are affected.

The model will only be briefly reviewed here. It is quarterly and contains estimated equations for 44 countries. Most of the equations 
TABLE 3. Estimates of $\rho_{j}$ and $\sigma_{\varepsilon j}$ for the First 15 Countries

for Each of the First 15 Equations

$\hat{\rho}_{j}$

Eq.

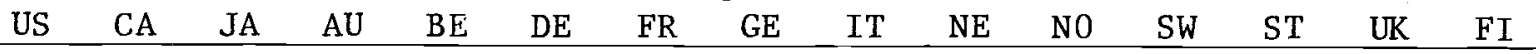

1 US U.S. $\quad--\quad-.38 \quad .00-.03-.46-.26-.43-.61-.35-.39-.18-.40-.22-.46-.40$

2 CA Canada $\quad-.26 \quad--\quad-.22 \quad-.19-.42 \quad-.28-.11-.52-.13-.35-.48-.44-.40-.29-.52$

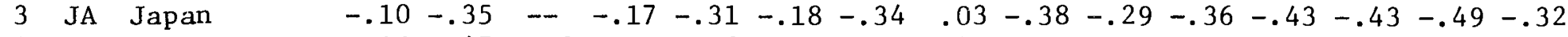

$4 \mathrm{AU}$ Austria $\quad-.36-.47-.09 \quad--\quad-.38-.19-.35-.40-.33-.36-.31-.45-.31-.42 \quad-.43$

5 BE Belgium $\quad-.49-.38-.12-.37 \quad--\quad-.47-.29-.27-.35-.31-.36-.37-.51-.45-.35$

6 DE Denmark $\quad-.36-.31-.10-.36-.57--\quad-.26-.32-.22-.30-.25-.16-.22-.41-.38$

7 FR France $\quad-.52-.17-.27-.07-.37-.25--\quad-.33-.50-.41-.44-.36-.37-.05-.43$

8 GE Germany $\quad-.22-.33-.04-.34-.55-.14-.27--\quad-.21-.40-.00-.32-.23-.44-.31$

9 IT Italy $\quad-.20-.39-.37 \quad .06-.18-.32-.03 \quad-.26 \quad--\quad-.28-.19-.38-.23-.26-.27$

$10 \mathrm{NE}$ Netherlands $\quad-.47 \quad-.45 \quad .00-.41-.66-.17-.35-.51-.31 \quad-\quad-\quad-.38-.48-.24-.08-.45$

11 No Norway $\quad-.43-.49-.33-.58-.44-.26-.29-.47-.51-.40--\quad-.57-.52-.41-.53$

12 SW Sweden $\quad-.39-.55-.30-.34-.38-.28-.42-.46-.61-.30-.62-0-.35-.25-.24-.54$

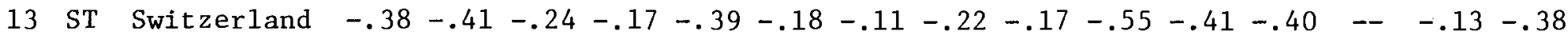

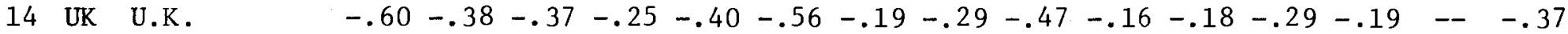

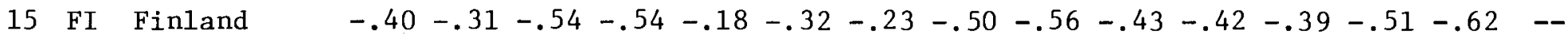

$\hat{\sigma}_{\varepsilon j}$

\begin{tabular}{|c|c|c|c|c|c|c|c|c|c|c|c|c|c|c|c|c|c|}
\hline $\mathrm{Eq}$ & & & US & $\mathrm{CA}$ & $\mathrm{JA}$ & $\mathrm{AU}$ & $\mathrm{BE}$ & $\mathrm{DE}$ & FR & $\mathrm{GE}$ & IT & $\mathrm{NE}$ & NO & SW & ST & UK & FI \\
\hline 1 & US & U.S. & -- & .08 & .09 & .17 & .14 & .11 & .10 & .11 & .11 & .12 & .23 & .16 & .10 & .10 & .30 \\
\hline 2 & $\mathrm{CA}$ & Canada & .04 & -- & .17 & .29 & .1 & .12 & .1 & .1 & .1 & .1 & .6 & .19 & & .10 & $\theta$ \\
\hline 3 & JA & Japan & .07 & .17 & -- & .33 & .18 & .28 & .13 & .08 & .26 & .17 & .39 & .19 & .13 & .13 & .65 \\
\hline 4 & $\mathrm{AU}$ & Austria & .22 & .32 & .16 & -- & .16 & .09 & .13 & .02 & .1 & .07 & .12 & .09 & .06 & .08 & .18 \\
\hline 5 & $\mathrm{BE}$ & $\mathrm{Be}$ & .10 & .25 & .16 & .10 & -- & .10 & .06 & .04 & .0 & .0 & .1 & .09 &. & .09 & .26 \\
\hline 6 & $\mathrm{DE}$ & Den & .21 & .26 & .37 & .09 & .15 & -- & .14 & .06 & .1 & .1 & .13 & .06 & .1 & .0 & .11 \\
\hline 7 & FR & Fra & .13 & .14 & .2 & .07 & .0 & .09 & - & .05 & .0 & .0 & .21 & .1 & .0 & .07 & .14 \\
\hline 8 & GE & $\mathrm{Ge}$ & .1 & .22 & .11 & .07 & .06 & .07 & .06 & -- & .10 & .0 & .17 & .06 & .05 & .08 & .10 \\
\hline 9 & IT & I & .1 & .15 & .17 & .09 & .14 & .20 & .07 & .05 & -- & .09 & .54 & .15 & .09 & .07 & .24 \\
\hline 10 & $\mathrm{NE}$ & $\mathrm{Ne}$ & $.1]$ & .24 & .22 & .12 & .07 & .09 & .10 & .04 & .13 & -- & .18 & .09 & .09 & .09 & .20 \\
\hline 11 & NO & & .18 & .48 & .94 & .16 & .15 & .10 & .35 & .10 & .20 & .40 & -- & .13 & .11 & .20 & .38 \\
\hline 12 & SW & S & .10 & .22 & .38 & .07 & .12 & .05 & .13 & .05 & .0 & .13 & .06 & - & .05 & .08 & .13 \\
\hline 13 & $\mathrm{ST}$ & Switzerlau & .19 & .21 & .14 & .08 & .10 & .10 & .08 & .05 & .1 & .09 & .12 & .08 & -- & .17 & .22 \\
\hline 14 & UK & & .10 & .15 & .21 & .07 & .12 & .10 & .11 & .10 & .12 & .12 & .29 & .10 & .07 & -- & .13 \\
\hline 15 & FI & Fin 1 and & .18 & .37 & .24 & .09 & .15 & .09 & .19 & .07 & .10 & .10 & .25 & .08 & .07 & .16 & -- \\
\hline
\end{tabular}

Note: $\sigma_{\varepsilon j}$ is in units of percent $(10$ percent $=.10)$. 
have been estimated by two stage least squares. The basic estimation period is 1958I-1980I. There are up to 11 estimated equations per country (excluding the U.S., for which there is a much larger mode1), explaining (1) imports, (2) consumption, (3) investment, (4) production, (5) GNP deflator, (6) money supply, (7) short term interest rate, (8) long term interest rate, (9) exchange rate, (10) forward rate, and (11) export price index. The part of the model that links the countries together receives as input from each country its level of imports, exchange rate, and export price index and returns as output the level of exports and the import. price index. The trade shares are used in the determination of both of these variables. The model is solved by iterating between the models of the individual countries and the part of the overall model that 1 inks the countries together.

When the share equations are added to the model, the estimates of $\rho_{j}$ cannot be used in the predictions of the shares. If they were used, it would not be the case that $\sum_{j \varepsilon A} \hat{\Delta \alpha}_{j i t}=0$. The error term u $_{j i t}$ in equation (1) must be set to zero for all $j$ and $t$ in order for this property to hold.

The fit of the model is examined in Table 4. The model was solved for three eight-quarter periods, both statically and dynamically, and root mean squared errors (RMSEs) were computed for each endogenous variable for each run. For the first set of results in Table 4 a weighted average of the RMSEs across all countries except the U.S. was taken for each variable. The RMSEs were weighted by the ratio of the country's real GNP (in 75\$) in the last (i.e., eighth) quarter of the prediction period to the total real GNP of all the countries. The RMSEs for the U.S. are presented in the second half of Table 4. 
TABLE 4. RMSES

STA = Static simulation

DYN = Dynamic simulation $\mathrm{a}=$ Trade shares exogenous

$\mathrm{b}=$ Trade shares endogenous

\begin{tabular}{|c|c|c|c|c|c|c|c|c|c|c|c|c|}
\hline & \multicolumn{4}{|c|}{$701 \frac{\text { Weighted RMSE }}{-714}$} & \multicolumn{4}{|c|}{5 for All Countries Except } & \multicolumn{4}{|c|}{ the U.S. } \\
\hline & \multicolumn{2}{|c|}{ STA } & \multicolumn{2}{|c|}{ DYN } & \multicolumn{2}{|c|}{ STA } & \multicolumn{2}{|c|}{ DYN } & \multicolumn{2}{|c|}{ STA } & \multicolumn{2}{|c|}{ DYN } \\
\hline & $\mathrm{a}$ & $\mathrm{b}$ & $\mathrm{a}$ & $\mathrm{b}$ & $\mathbf{a}$ & $\mathrm{b}$ & a & $\mathrm{b}$ & $\mathbf{a}$ & $\mathrm{b}$ & a & $\mathrm{b}$ \\
\hline Rea1 GNP & 1.95 & 2.47 & 4.32 & 4.16 & 2.10 & 3.08 & 3.29 & 6.07 & 1.90 & 2.26 & 3.71 & 4.32 \\
\hline GNP Deflator & 0.81 & 0.80 & 2.53 & 2.36 & 1.19 & 1.17 & 2.28 & 2.97 & 0.98 & 0.99 & 2.60 & 2.70 \\
\hline Interest Rate & 0.56 & 0.57 & 0.91 & 0.89 & 0.75 & 0.88 & 1.14 & 2.43 & 0.88 & 0.89 & 1.80 & 1.88 \\
\hline Exchange Rate & c & $c$ & c & $c$ & 3.80 & 3.23 & 5.26 & 5.07 & 2.56 & 2.73 & 4.32 & 5.33 \\
\hline Import Price & 0.66 & 2.23 & 1.66 & 3.28 & 2.97 & 2.78 & 4.42 & 4.90 & 2.17 & 2.30 & 3.85 & 4.68 \\
\hline Money Supp1y & 2.99 & 2.93 & 6.60 & 5.85 & 2.85 & 2.92 & 3.87 & 3.67 & 2.55 & 2.57 & 3.83 & 4.14 \\
\hline Imports & 4.70 & 4.82 & 9.43 & 8.43 & 4.79 & 5.03 & 6.44 & 9.85 & 4.30 & 4.41 & 6.56 & 7.08 \\
\hline Consumption & 1.85 & 1.93 & 3.77 & 3.56 & 2.32 & 2.49 & 3.28 & 4.28 & 1.92 & 1.92 & 3.95 & 4.25 \\
\hline Investment & 4.07 & 4.19 & 10.28 & 8.26 & 4.21 & 4.49 & 7.67 & 9.92 & 3.41 & 3.64 & 7.79 & 7.85 \\
\hline Interest Rate & 0.27 & 0.27 & 0.49 & 0.48 & 0.43 & 0.55 & 0.74 & 1.28 & 0.41 & 0.40 & 0.90 & 1.02 \\
\hline Export Price & 1.81 & 1.80 & 3.87 & 3.75 & 3.71 & 3.41 & 5.14 & 5.31 & 2.66 & 2.65 & 4.34 & 4.73 \\
\hline \multirow[t]{4}{*}{ Exports } & 1.97 & 8.15 & 5.21 & 10.97 & 2.18 & 10.22 & 3.00 & 14.76 & 1.50 & 6.93 & 2.65 & 7.90 \\
\hline & \multicolumn{8}{|c|}{ RMSEs for the U.S. } & \multirow{2}{*}{\multicolumn{4}{|c|}{$761-774$}} \\
\hline & \multicolumn{2}{|c|}{ STA } & \multicolumn{2}{|c|}{ DYN } & \multicolumn{2}{|c|}{ STA } & DYN & $\mathrm{YN}$ & & & & \\
\hline & a & $\mathrm{b}$ & a & $\mathrm{b}$ & $a$ & $\mathrm{~b}$ & a & $b$ & a & $b$ & a & $b$ \\
\hline Real GNP & 0.50 & 0.49 & 0.25 & 0.81 & 0.81 & 0.71 & 2.31 & 3.16 & 0.74 & 0.76 & 1.32 & 0.93 \\
\hline GNP Deflator & 0.27 & 0.29 & 0.32 & 0.30 & 0.33 & 0.34 & 1.23 & 1.13 & 0.37 & 0.37 & 0.80 & 0.76 \\
\hline Interest Rate & 0.54 & 0.57 & 0.84 & 1.11 & 0.57 & 0.51 & 0.83 & 1.04 & 0.25 & 0.23 & 0.31 & 0.43 \\
\hline Import Price & 0.65 & 1.89 & 2.06 & 2.87 & 1.28 & 1.68 & 3.53 & 3.38 & 0.61 & 0.74 & 0.95 & 0.68 \\
\hline Money Supply & 1.15 & 1.15 & 3.37 & 3.41 & 1.02 & 1.02 & 0.83 & 0.82 & 0.66 & 0.66 & 1.07 & 1.02 \\
\hline Imports & 2.48 & 2.37 & 4.44 & 3.59 & 4.40 & 4.37 & 8.06 & 8.95 & 2.32 & 2.30 & 4.48 & 3.82 \\
\hline Interest Rate & 0.28 & 0.29 & 0.37 & 0.43 & 0.28 & 0.26 & 0.33 & 0.35 & 0.12 & 0.12 & 0.31 & 0.39 \\
\hline Export Price & 1.03 & 1.10 & 1.87 & 2.01 & 1.97 & 1.99 & 6.01 & 5.82 & 1.15 & 1.15 & 2.32 & 2.32 \\
\hline Exports & 1.14 & 6.73 & 1.87 & 13.59 & 1.68 & 4.64 & 2.64 & 9.00 & 1.33 & 3.26 & 2.20 & 6.71 \\
\hline
\end{tabular}

Notes: 1. A11 errors are in percentage points.

2. Weights are GNP in $75 \$$ in the last quarter of the period.

3. First set of equations in Table 2 was used for the endogenous trade share case. The shares for the three countries with the wrong sign for $\hat{\beta}_{i}$--Yugoslavia, Mexico, and China--were taken to be exogenous.

$c=$ fixed exchange rate period for almost all countries. 
The variable most affected by the addition of the trade share equations is (as expected) the level of exports. For the 1976I-1977IV period, for example, the RMSE increased for the dynamic simulation from 2.65 percent to 7.90 percent. The effects on the other variables were much smaller, and in some cases error cancellation was such as to lead to smaller RMSEs in the endogenous trade share case. Of the other variables, GNP was generally affected the most. This is, of course, not surprising given that exports are part of GNP.

For the results in Fair (1981b), ten experiments were performed, each experiment corresponding to a change in one or more exogenous variables. Trade shares were taken to be exogenous for these results. For present purposes these experiments were repeated with the trade share equations added. The results of two of the experiments are reported in Tables 5 and 6 . For the first experiment the equation explaining the German exchange rate was dropped and the German exchange rate was taken to be exogenous. The results in Table 5 are for an increase in the exchange rate of ten percent (a depreciation). The second experiment is the same as the first except the country is the U.K. instead of Germany. The results of this experiment are presented in Table 6.

All of the countries in the model were used for the experiments. The results for 15 countries and 13 variables per country are presented in Tables 5 and 6 for the two-quarter-ahead and six-quarter-ahead predictions. Except for the numbers for the balance of payments, each number in the tables is the percentage change in the variable (in percentage points).

Without a detailed description of the model, it is not possible to explain all of the results in the two tables. This description is 


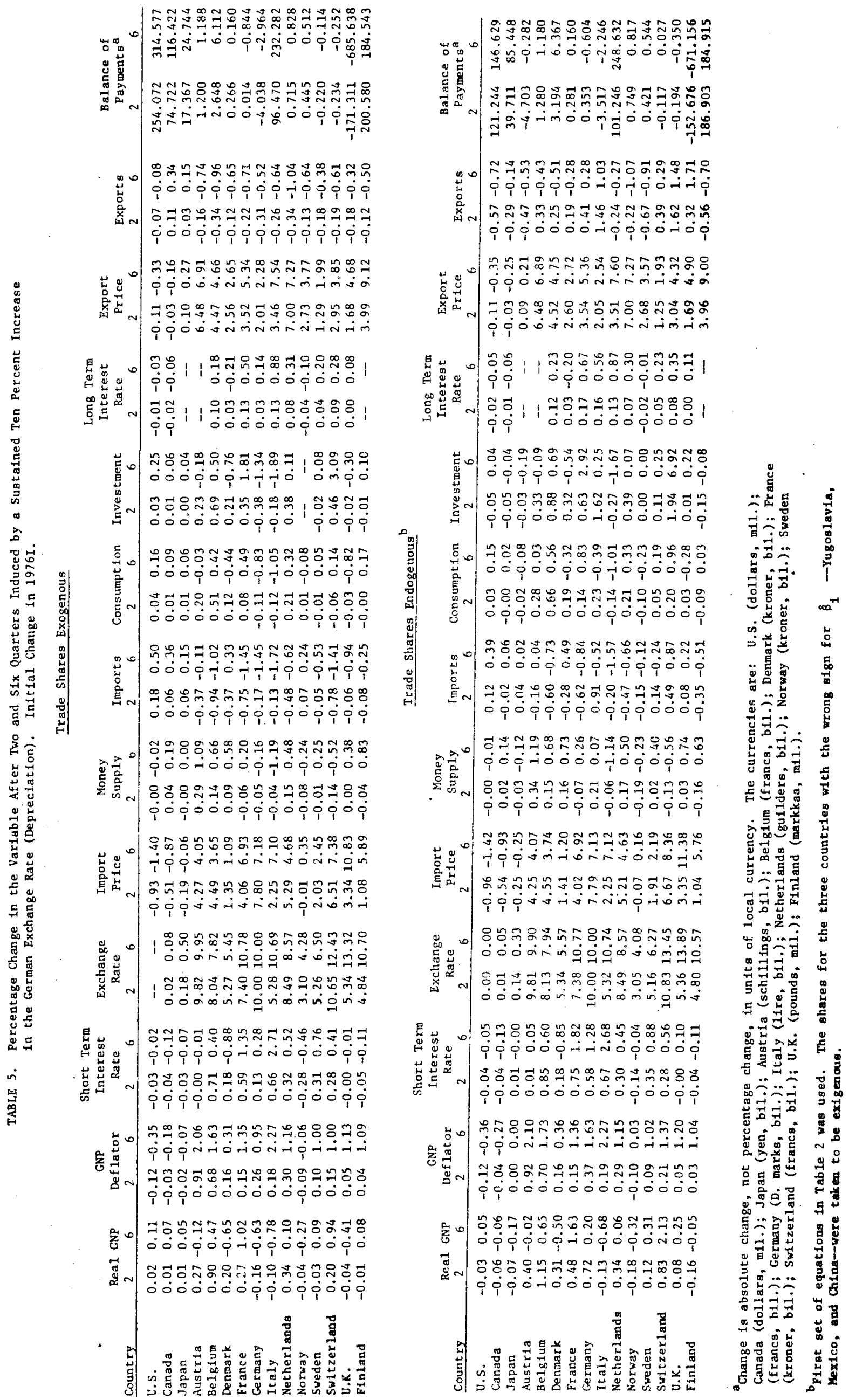




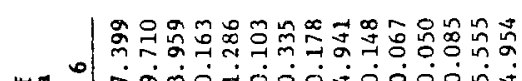

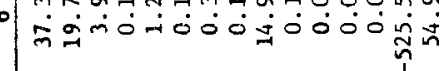

密

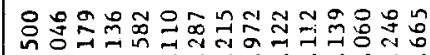

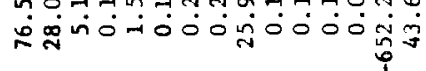

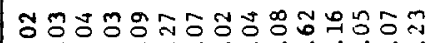

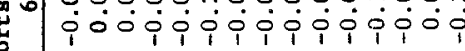

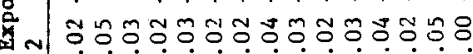
00000

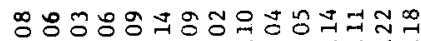

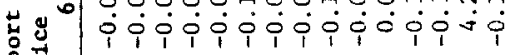

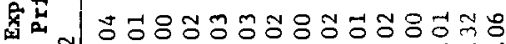

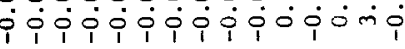
思嫣

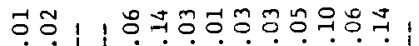

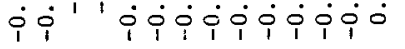

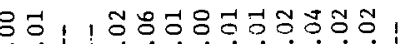

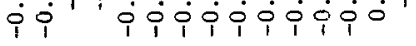

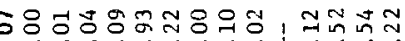

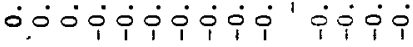

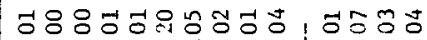

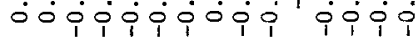

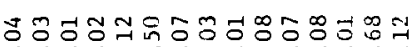
- 0 o jo jo

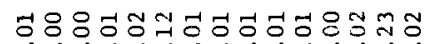

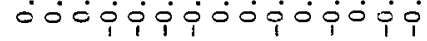

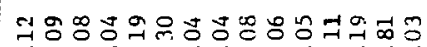

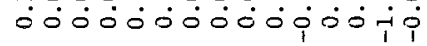

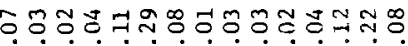
ல0:00000000000

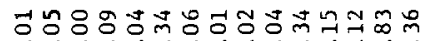

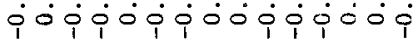

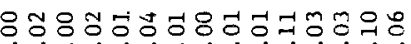
iói ípói

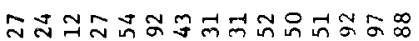

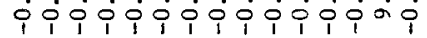
兽点 N N

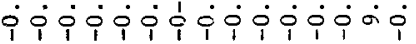

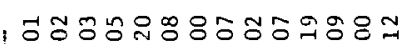

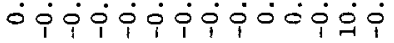

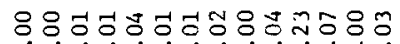
- 0 i

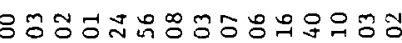

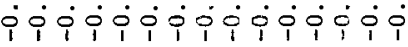

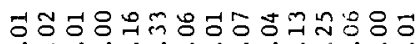
ióipipipiói

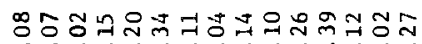
iojópóiojói

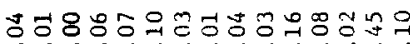

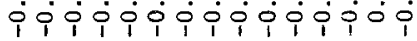

岁 -

ஐ -00ipióiojipipi

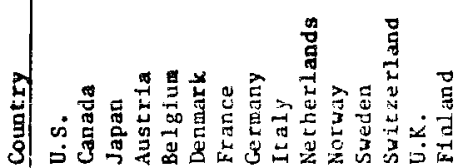

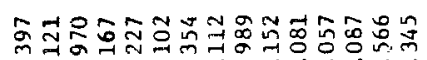

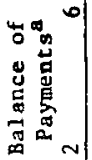
भि

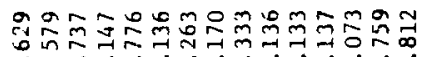
ठ்

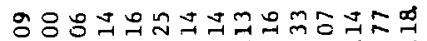
出

离 í⿴囗i

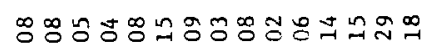

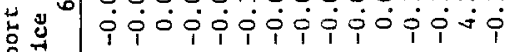

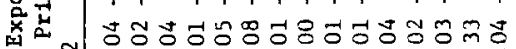

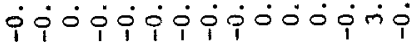

至

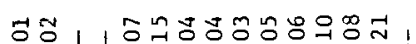
لإ 次

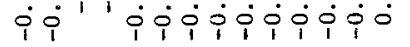

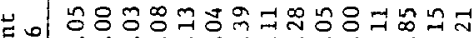

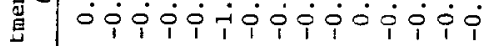
结

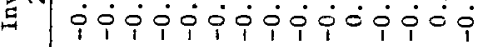

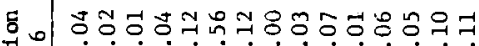

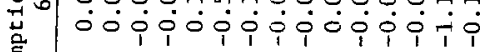

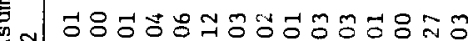

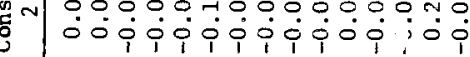

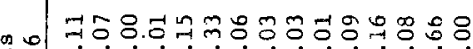

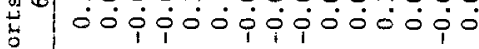

畐㓊

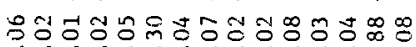
ó0

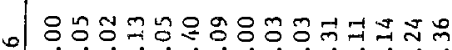

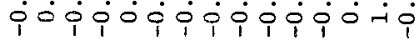

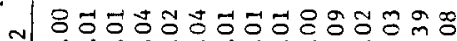

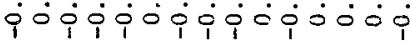

范热

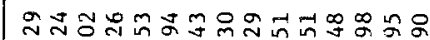

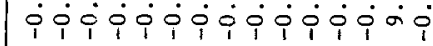

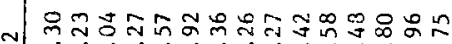

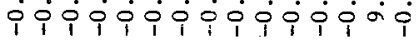
总

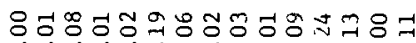

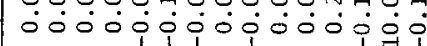

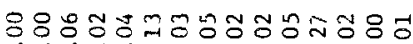

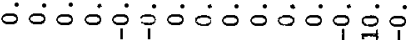

苞 ثै 岩岂䍃 I 茑总

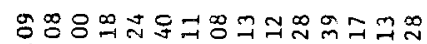

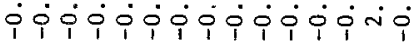
出 $N$ 1000=000

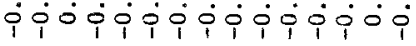

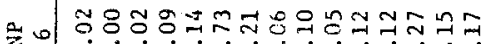

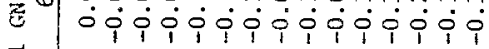

羿 -

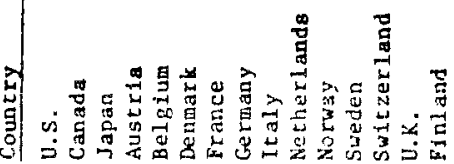


provided in Fair (1981a, 1981b). For present purposes the discussion will be 1imited to two effects: the effect on the balance of payments and the effect on GNP. The initial effect of a depreciation on the balance of payments is likely to be negative in the model. Depreciation raises the local currency price of imports more than it does the local currency price of exports, which, other things being equal, has a negative effect. on the balance of payments. Depreciation also lowers imports and raises exports, which has a positive effect on the balance of payments. This latter effect is likely to be smaller initially than the price effect, and so the initial net effect is likely to be negative. (This is the "J curve" effect.) This is true of the results in Tables 5 and 6 , where the changes in the balance of payments of Germany in Table 6 and of the U.K. in Table 7 are negative. The balance of payments falls less when the trade shares are endogenous because the changes in exports are greater. In the endogenous trade share case, the share of the depreciating country's exports in other countries' imports rises because of the fall in the relative price of the depreciating country's exports. This is the first main difference between the two cases.

Depreciation has three main effects on GNP in the model, two positive and one negative. The first effect is through the price of imports. Depreciation raises the price of imports, which has a negative effect on the demand for imports, which has a positive effect on GNP. In other words, an increase in the price of imports causes substitution from imports to domestically produced goods, which raises GNP. The second effect is through the price of exports. Depreciation lowers the foreign currency price of exports. If trade shares are endogenous, this increases the demand for the country's exports, which raises GNP. Although this effect is 
lacking when trade shares are exogenous, there is still at least a slight increase in the country's exports, other things being equal. The decrease in the price of exports lowers the import price indices of countries that import from the given country, which in turn increases their demand for imports. Some of this increase in demand (even with trade shares exogenous) is an increase in demand for the given country's exports.

The third effect is through the balance of payments. If depreciation lowers the balance of payments, this decreases the country's net foreign assets, which in the model decreases the demand for imports and consumption and increases the short term interest rate. Although the decrease in imports raises GNP, the decrease in consumption and the increase in the interest rate lower GNP, and the net effect is likely to be negative. Although the net effect of a depreciation on GNP can go either way, it is more likely to be positive when trade shares are endogenous than when they are exogenous. The positive export effect is larger in the endogenous case and the negative balance of payments effect is smaller (because the decrease in the balance of payments is smaller). This is in fact the case in Tables 5 and 6 . In the German experiment with trade shares exogenous, GNP fell by 0.16 percentage points after two quarters and 0.63 percentage points after six quarters. With trade shares endogenous, GNP rose by 0.72 percentage points after two quarters and 0.20 percentage points after six quarters. In the U.K. case with trade shares exogenous, GNP fell by 0.09 and 0.70 in the two quarters, respectively. With trade shares endogenous, GNP rose by 0.62 after two quarters and fell by 0.15 after six quarters.

The differences in the results between the endogenous and exogenous trade share cases are larger in the depreciation experiments just reported 
than they are when the experiment is a change in government spending or in monetary policy. Changes in fiscal and monetary policy do not change the relative price of a country's exports nearly as much as does a depreciation, and so the results are obviously less sensitive to the treatment of trade shares.

\section{Conclusion}

The results in Table 2 indicate that relative prices have an important effect on trade shares. The sensitivity of trade shares to relative prices thus appears to be an important channel through which a country's price of exports affects the demand for its exports. This channel is evident in the multicountry model discussed in Section $V$, where the addition of the trade share equations has noticeable effects on the properties of the model regarding the effects of a depreciation. 


\section{REFERENCES}

Armington, Paul S. "A Theory of Demand for Products Distinguished by P1ace of Production," International Monetary Fund Staff Papers (March 1969) : 159-176.

Fair, Ray C. "A Multicountry Econometric Mode1," Cowles Foundation Discussion Paper No. 541R, revised April 30, 1981. (a)

- "Estimated Output, Price, Interest Rate, and Exchange Rate Linkages among Countries," Cowles Foundation Discussion Paper No. 592, April 30, 1981. (b)

Kmenta, Jan. Elements of Econometrics. New York: The Macmillan Co., 1971.

Oberhofer, W. and J. Kmenta. "A General Procedure for Obtaining Maximum Likelihood Estimates in Generalized Regression Models," Econometrica 42 (May 1974): 579-590.

Samuelson, Lee. "A New Model of World Trade," OECD, Economic Outlook, Occasional Studies, December 1973: 1-22.

Taplin, G. B. "A Model of World Trade." In The International Linkage of National Economic Models, edited by R. J. Ball. Amsterdam: North-Holland, 1973. 